\title{
ZOOGDIEREN UIT DE ONDERST-PLEISTOCENE KUSTSTREKEN VAN NEDERLAND
}

\author{
(with English summary) \\ DOOR \\ DR. A. SCHREUDER
}

Het onderzoek der mariene mollusken en foraminiferen uit boringen in Zeeland, Noordbrabant en Gelderland heeft aangetoond, dat bij de nadering van de Günzglaciatie, dus bij de overgang van het Plioceen naar het Pleistoceen, de Noordzee zich uit de Belgische Kempen en het zuiden van ons land teruggetrokken heeft. Zijn kust verplaatste zich geleidelijk westwaarts over het IJsseldal en noordwaarts over het zuiden van Zeeland en Noordbrabant. Zo zijn er thans fossiele resten daar in de ondergrond te verwachten van kustdieren als robben, zowel in ons land als in de buurt van Antwerpen en in de Belgische Kempen. En wel in grote getale, want het tempo waarin die kust zich verplaatste was dusdanig, dat zouden er te dien tijde mensen hier hebben geleefd (wat vrij zeker niet het geval is geweest), hun die kust even onveranderlijk zou hebben geleken, als hij zich thans aan ons voordoet en op de kaarten kan worden getekend. Het is dan ook gedurende honderdduizenden jaren, dat robben in kudden in het huidige zuiden van Nederland konden voorkomen. Stromer von Reichenbach (I939) toch geeft voor de duur van het Plioceen globaal I 800000 jaar aan. De duur van de bovengenoemde zeeregressie kunnen we veilig op enkele honderdduizenden jaren schatten, evenals de duur van de daarop gevolgde transgressie, toen de Icenienzeekust met zijn bewoners zich weer bijna tot zijn vroegere stand zuidwaarts verplaatste, waarschijnlijk een gevolg van het afnemen van de Günz I glaciatie en het bestaan van het Günz-interstadiaal.

De Belgische geo-palaeontoloog Georges Hasse schreef (I9IO, 'I I) over de walrusachtige fossielen, die gevonden werden bij het graven van verdedigingswerken bij Antwerpen in het „Pliocène poederlien”, een kustfacies van het eronder gelegen Bovenplioceen (Scaldisien). Ook in Zeeland en in het westen van Noordbrabant kon het Poederlien worden aangetoond (tussen Scaldisien en Icenien) daar waar het Amstelien ontbreekt (TEN DAM en Reinhold, I94I, p. 26) en wel als een 4 à $5 \mathrm{~m}$ dikke laag op Walcheren bij Biggekerke en bij Vlissingen, op een diepte van $25-30 \mathrm{~m}$, en als een $20-30 \mathrm{~m}$ dikke afzetting bij Roozendaal en bij Breda op diepten van 80-IO0 m; bij Antwerpen ligt het Poederlien slechts enkele meters onder de oppervlakte. 
Alle fossiele walrusoverblijfselen van Antwerpen brengt Hasse tot het geslacht Alachtherium, dat ook voor ons land geconstateerd kon worden door Van Deinse (De Levende Natuur, Nov. en Dec. I943 en Febr. en Mrt. '44) aan verschillende beenderen uit de Zeeuwse wateren.

De eerste walrusschedel, uit de Westerschelde bij Breskens opgevist, werd in 1907 door RutTEN toegeschreven aan Trichechus (Odobenus) huxleyi, een uitgestorven soort van het geslacht Odobenus, die reeds bekend was van het Engelse Red Crag.

Beide onder de „zwarte fossielen” voorkomende walrussen zijn dus afkomstig uit de Zeeuwse wateren, de rijkste bronnen der Nederlandse oudste pleistocene zoogdieren. In de diepte der Scheldearmen toch worden door de stromen zelfs tertiaire lagen uitgekolkt, plaatselijk wel tot een diepte van 60-100 m. De fossielen komen dan vrij en kunnen door sleepnetten naar boven worden gehaald. Op deze wijze zijn er reeds lang uit plio- en pleistocene lagen van verschillende ouderdom fossielen van grote zoogdieren, zoals dolfijnen, olifanten, mastodont, walrussen, runderen, reuzehert, nijlpaard, enz. geborgen kunnen worden. Maar de resten van de kleine soorten stromen met het water weer door de mazen weg. Eerst onlangs is uit de Schelde een halve fossiele humerus van een hermelijntje in het Leidse Geologische Museum in veiligheid gebracht, dat door Drs. P. H. Creutzberg, te Leiden, werd gevonden in een hoop schelpen, afkomstig van een schelpenzuiger, die in de Westerschelde lag bij Ellewoutsdijk. Hoewel niet pikzwart, is dit botje toch zeer donker bruin, donkerder dan de beenderen uit de Tegelse klei. Kon men maar geregeld op de hoogte worden gehouden, waarheen de opgezogen schelpen, die bestemd zijn voor wegverharding, kalkbranderijen of kippengrit, worden vervoerd, dan zou er in die hopen gezocht kunnen worden naar botjes of kiezen, die tussen de lichtgekleunde schelpen gemakkelijk te onderkennen zijn. Tot nu toe gaat al dat kostbare materiaal verloren.

Behalve uit de Schelde zijn er ook enkele onderst-pleistocene zoogdierresten uit boringen te voorschijn gekomen. Deze bron is wel het waandevolst, omdat de juiste geologische ouderdom van het fossiel dan met groter zekerheid kan worden vastgesteld, dan dat bij de uitgespoelde stukken het geval is.

De ,zwarte fossielen” zijn sterk verkiezeld en door hun kleur meestal gemakkelijk te onderscheiden van de fossielen uit de Tegelse klei. Dit is ook het geval met de stukken uit de boringen. Het eerst was bekend een zwart humerusfragment van een walrus uit een boring te Deventer, van een diepte van II $7 \mathrm{~m}$ uit een laag, die boven het Scaldisien is gelegen en mogelijk de kustfacies daarna, het Poederlien, vertegenwoondigt (Dr. J. F. Steenhuis in litt. '48). Het mariene Amstelien ontbreekt in deze boring, evenals in Zeeland en in de buurt van Antwerpen, waar de zwarte walrusbeenderen werden gevonden temidden van littorale mollusken.

Het tweede zwarte fossiel uit een boring is een hoornpit van een gazelle van een diepte van 6I $\mathrm{m}$ uit een boring naar drinkwater in Grubbenvorst, ten 
noorden van Venlo, aan de Maas. Deze diepte behoort tot het fluviatiele Plioceen, is prae-Günz en hoogstwaarschijnlijk gelijk te stellen met bovengenoemde diepte in de boring van Deventer en met de formatie waaruit in Zeeland en de Antwerpse Kempen de zwarte fossielen te voorschijn l:wamen.

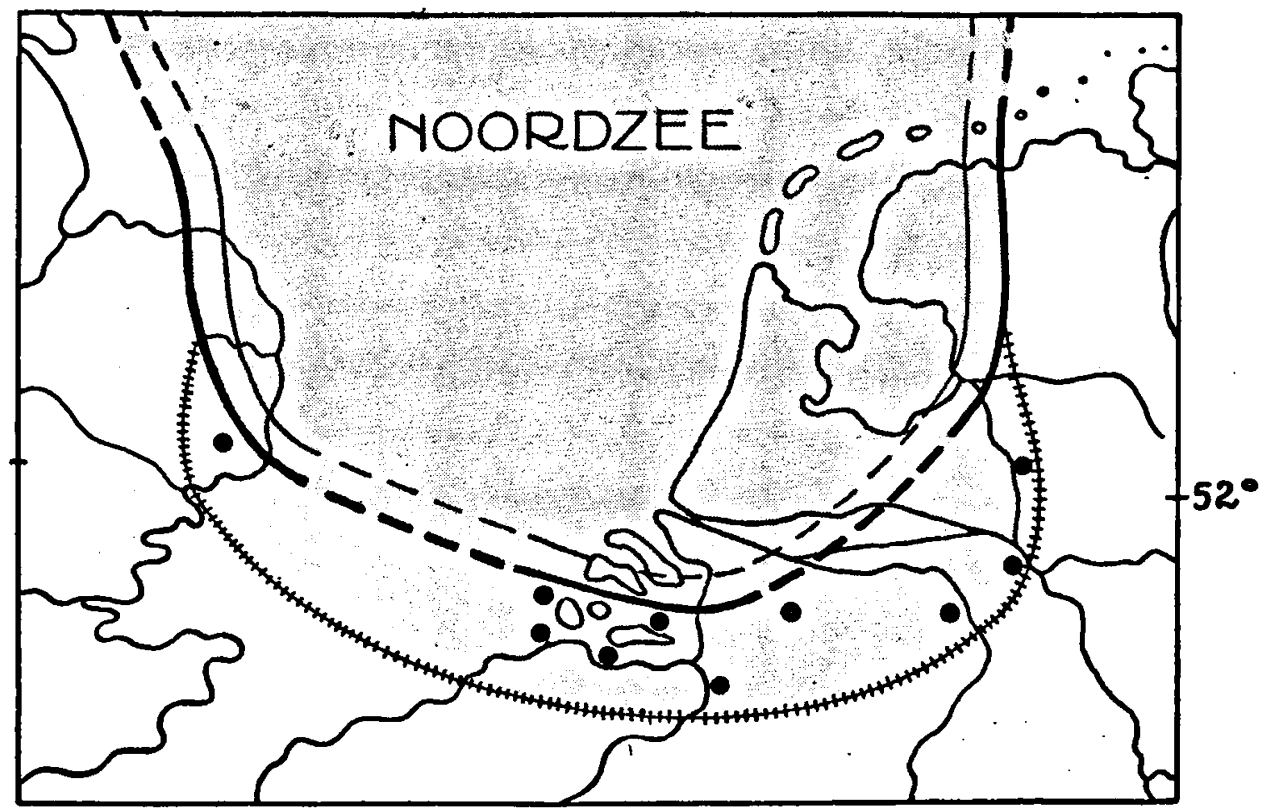

De Noordzee tijdens het Plio-Pleistoceen volgens TEsCH (1942).

De dwarsgestreepte lijn duidt de kustlijn aan in het Scaldisien (Boven-Plioceen), de strakke lijn die in het Amstelien (Onder-Pleistoceen). De stippen geven de plaatsen aan waar foss:ele zoogdieren behorend tot de Onder-Villafranchien fauna zijn gevonden. Van west naar oost: Red Crag (Woodbridge) in Suffolk, Roompot (en Put van Oostkapelle), Oosterschelde bij Ierseke, Wielingen bij Breskens (en Oostgat bij Zoutelande), Westerschelde bij Terneuzen, Antwerpen, Belgische Kempen (Ryckevorsel, Beerse, Merxplas, etc.), Grubbenvorst (boring) bij Venlo, Beneden-Rijn en Deventer (boring).

Vertegenwoordigers van deze Onder-Villafranchien fauna zijn dus thans bekend uit het zuiden van Nederland en van even over de Belgische en de Duitse grens en wel van de Zeeuwse wateren, de buurt van Antwerpen, de Antwerpse Kempen, uit de ondergrond van Midden-Limburg, uit de BenedenRijn en ten laatste uit de ondergrond van het IJsseldal. Aldus is de gaping tussen de verspreiding der onderst-pleistocene zoogdieren onder in het Engelse Red Crag en de prae-Günz-glaciale zanden in Thüringen, met Anancus arvernensis, op gelukkige wijze aangevuld.

Van deze Onder-Villafranchien fauna, zijn, in chronologische volgorde, thans de volgende soorten uit Nederland bekend geworden:

I. Eucladoceros (Cervus) falconeri Dawk., geweitakken en fragmenten daar- 
van (Dubois, I905, Pl. II ; Kunst, I937, pp. Ior, etc., Pl. IV) = Cervus ertborni (Dubois, I907, I Pl.; Teilhard en Piveteau, I932, 5 t.fig.); Mus. Zeeuws Gen., Middelburg en Rijksmus. v. Geologie, Leiden, bewaren die uit Zeeland ( $\mathrm{R}$ o o $\mathrm{mpot}$ ); die uit de $\mathrm{B}$ elg. $\mathrm{Ke} \mathrm{m}$ pe $\mathrm{n}$ (B e e rse, M e rxplas, etc.) bevinden zich in het Musée d'histoire naturelle te Brussel, waar zich van daar ook een linker onderkaak met gebit bevindt en in Teylers Museum te Haarlem, dat ook enkele extremiteitenbeenderen (distaal einde van radius, astragalus, cubonaviculare en phalanx) herbergt.

2. Odobenus (Trichechus) huxleyi, drie schedels (Rutten, I907, I Pl.; VAN Deinse, 1935, p. 298 en I943-'44, 6 t.fig.). Coll. Geol. Inst., Utrecht en Museum v. Oudheden, Vlissingen. Mond van Westerschelde. 3. Odobenus spec., a. humerusfragment (VAN DEINSE, I93I, p. IO6 en I943'44, I t.fig.) Coll. Van Deinse, Rotterdam. Boring bij Deventer. b. fragmenten van twee canini (VAN Deinse, I943-'44, 2 t.fig.). Coll. van Beveren, Vere, en Geol. Inst., Utrecht. Put v. O os tka pelle. c. Staartwervel (VAN Deinse, I943-'44, p. 86). Coll. Gymnasium Erasmianum, Rotterdam. Westerschelde bij Terneuzen. 4. Anancus (Mastodon) arvernensis Croiz. et Job., twee bovenkiezen ${ }^{1}$ ) (VaN Der Vlerk, 1938, p. Io; Schreuder, I944, Pl. III, I textf. en I945b, I textf.). Coll. Rijksmus. v. Geol., Leiden, no. St. 50478 en Mus. Zeeuws Gen., no. 1562, Middelburg.

Oosterschelde bij Ierseke en "voor Domburg”. Het laatste exemplaar zal op p. ro kort worden beschreven. Het kiesfragment ( $\mathrm{m}^{3}$ sin., no. I35 $\mathrm{I}$, Mus. te Middelburg) uit de Beneden-Rijn (Schreuder, 1944, p. 46, Pl. III, fig. 2) behoort zeker niet tot de „zwarte" fossielen, want de kleur is licht grijs. Ook is deze kies breder dan de exemplaren uit Zeeland, die volkomen overeenkomen met die uit het Red Crag.

5. Archidiskodon (Elephas) planifrons, onderkies (Schreuder, I944, Pl. IV en I t.fig.). Coll. Rijksmus. v. Geologie, Leiden; no. St. 20033.

Oosterschelde bij I erseke.

6. Alachtherium spec., a. femur (VAn Deinse, I943-44, I t.fig.). Coll. v. Beveren, Vere.

Put van Oostkapelle.

b. halswervel (ibid. 4 t.fig.). Coll. Van. Deinse no. I35. R o o m p ot.

c. humerusfragment (ibid.). Coll. Rijksmus. v. Geologie, Leiden no. St. 20032.

Oosterschelde bij Ierseke.

I) Het kiesfragment in het Middelburgse Museum (Schreuder, 1944, p. 45), gemerkt "No. 1846: winter I934-'35", blijkt niet van een mastodont te zijn, maar van een olifant. Deze is geen Archidiskodon, maar moet, mede gezien de veel minder sterke graad van fossilisatie dan de zwarte fossielen vertonen, afkomstig zijn van een geologisch vrij jonge olifant, mogelijk van de mammoeth, waarvan meer kiezen uit de Zeeuwse wateren zijn opgevist. 
d. fragment van tibia en van humerus (Dr. A. B. van Deinse en Dr. D. A. Hoorjer in litt., Juni 1948). Coll. Rijksmus. v. Geologie, Leiden, no. St. 28449 en 20198. "Z e euwse wateren". 7. Gazella schreuderae, hoornpit (Hoorjer, 1945, I fig.). Coll. Geol. Stichting, Haarlem.

Boring Grubbenvorst, I9I8. 8. Mustela erminea, halve humerus (Dr. D. A. Hooljer in litt., Juni '48). Coll. Rijksmus. v. Geologie no. St. 53i88, Leiden. We ster's chelde bij E 11 e w o u t s dij k.

Ook dit stuk zal hieronder nog ter sprake komen.

Evenals van de Boven-Villafranchien zoogdierfauna uit de Tegelse klei (1904), was het dus ook van deze Onder-Villafranchien fauna, dat EugÈNE DuвоIs het eerst een overblijfsel van een vertegenwoordiger beschreef en wel in 1905, van het grote hert uit de klei van Ryckevorsel in de Antwerpse Kempen, Cervus falconeri.

Eucladoceros falconeri is nog niet oostelijk van de Antwerpse Kempen aangetroffen, echter wel westelijk, want in het Middelburgse en in het Leidse Museum kon Kunst (1937) een negental geweifragmenten meten, die zij ten dele ook afbeeldde (pl. IV). Al deze stukken zijn opgevist uit de Roompot, een stroom in de mond van de Oosterschelde, langs de noordkust van Walcheren. Zooals bekend ontbreekt op Walcheren het Amstelien in de ondergrond, maar daar op 25-30 m diepte het Poederlien er aangetroffen is, ligt het voor de hand aan te nemen, dat de fossiele herten uit die formatie afkomstig zijn. Dit voorkomen is de schakel tussen dat in de Antwerpse Kempen en in het Nodule Bed van het Engelse Red Crag, waaruit zich in het Britse Museum verscheidene stukken bevinden, evenals uit het Norwich Crag.

Enige opheldering past hier over het in dit artikel onderpleistoceen noemen der zwarte fossielen, die ik in 1944 en in 1945 (p. 444) nog als bovenplioceen betitelde. Dit geschiedide toen ter wille van de nationale eenheid, want ik volgde daarmee de indeling van de Nederl. Geol. Kaart, hoewel het uit palaeontologisch oogpunt gezien, niet wenselijk was het Villafranchien zodoende voor de helft (de zwarte fossielen) in het Plioceen en voor de andere helft (Tegelen) in het Pleistoceen te plaatsen. Daar er nu echter op het in September te Londen gehouden Intern. Geol. Congres een resolutie is aangenomen (OAKLEY, I949), waarbij de grens tussen Plioceen en Pleistoceen komt te liggen onder het $g e$ hele Villafranchien, sluit ik mij daar gaarne bij aan. Te meer daar reeds voor de bijeenkomst van bovengenoemd congres Dr. Tesch mij mededeelde, dat hij hoopte en verwachtte, dat de grens zou worden vastgesteld onder het Amstelien, want dat dan ook de uitwerking van de Alpiene tectogenese in dit deel van Europa goed merkbaar begint te worden en de landverbinding met Engeland versterkt wordt door de opwelving van de antikline Boulonnais-Kent. 


\begin{tabular}{|c|c|c|c|}
\hline & Engeland & Z.W. Nederland en Antw. Kempen & Overig Nederland \\
\hline 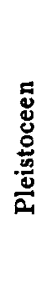 & $\begin{array}{l}\text { Weybourne Crag } \\
\text { Norwich Crag }\end{array}$ & $\begin{array}{l}\text { Noordzee-regressie } \\
\text { Icenien transgressie }\end{array}$ & $\begin{array}{l}\text { Günz II } \\
\text { Günz-interstadiaal } \\
\text { Tegelse Klei met } \text { Arch.mer. } \\
\text { (arch. type), Eucl. tegul. } \\
\text { Cervus rhenanus, Mim. } \\
\text { plioc., etc. } \\
\text { (Boven-Villafranchien) }\end{array}$ \\
\hline \multirow[b]{2}{*}{ 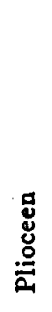 } & 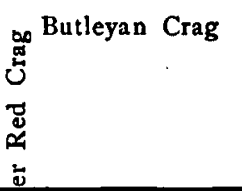 & $\begin{array}{l}\text { *) Poederlien (kustfacies met } \\
\text { Alachth., Arch. plan., Anancus } \\
\text { arv. Eucl. falc., Cerv. pardin.) } \\
\text { (Onder-Villafranchien) }\end{array}$ & $\begin{array}{c}\text { Günz I } \\
\text { Amstelien regressie } \\
\text { Calabrien }\end{array}$ \\
\hline & $\begin{array}{l}\text { Wewbourn Cag } \\
\text { Walton Crag }\end{array}$ & Scaldisien & \\
\hline
\end{tabular}

De stippellijn duidt de grens tussen Plioceen en Pleistoceen aan volgens de Nederlandse Geologische kaart.

De vaste lijn de grens vastgesteld op het Intern. Geol. Congres te Londen, September 1948.

In de bovenstaande tabel heb ik dan ook nu de plaats van de grens gekozen, die ik in I944-'45 aangaf op de tabellen als de grenslijn van Haug, Pilgrim, Hopwood, Dietrich, Motrl, e.a. en waarbij het Plioceen gekenmerkt wordt door het optreden in Europa van zoogdieren als Elephas.(Archidiskodon), Equus en Leptobos. In Engeland is het de onderste laag van het Red Crag, het Nodule Bed, dat dezelfde Onder-Villafranchien zoogdieren heeft opgeleverd als de Nederlandse ,zwarte fauna”. Het direct onder dit Nodule Bed gelegen Waltonian Crag wordt door enige Engelse geologen al tot het Pleistoceen gerekend op grond van zijn inhoud aan Foraminiferen. Ook Prof. VAN DER VLERK acht (in litt.) dit standpunt voorlopig niet onaanvaardbaar, al verdedigde hij op bovengenoemd congres de grens tussen Newbourn en Butleyan Crag.

*) De Onder-Villafranchien fauna heet hier Poederlien, hoewel ik hem in '44 en '45 op de tabellen Amstelien noemde. De reden is, dat HASSE zijn zwarte walrusfossielen bij Antwerpen in situ vond in „Pliocène Poederlien" en dat het voor de hand ligt, dat die, ook hier in de Schelde opgeviste, walrus afkomstig is, uit daarin uitgekolkte Poederlienlagen, die ik op grond van hun Onder-Villafranchien fauna tot het Ple:stoceen reken, dat dan aanvangt als de Scaldisien-zeekust zich noordwaarts begint terug te trekken; een bewijs van toenemende ijsvorming aan de pool (Günz I). Aanwijzingen van een naderend boreaal klimaat treden ook al op onder de Foraminiferen van het Poederlien. Amstelien komt nòch in Zeeland (behalve Schouwen), nòch in België voor, evenmin als in beide genoemde boringen. 
Het Poederlien wordt in Nederland, waar het in het uiterste zuidwesten voorkomt, bedekt door het mariene Icenien, want de Noordzee transgredeerde na het Günz I weer over de streken, die tijdens het Amstelien droog kwamen te liggen, maar verder dan ongeveer de Belgisch-Nederlandse grens kwam die transgressie niet. Zo is het bovenste Plioceen en het onderste Pleistoceen in de Belgische Kempen volgens TAvernier (1943, tabel op p. 26) ontwikkeld als de zanden van Mol, waarin CaIlleux (1942) een glaciaal niveau meent te kunnen aantonen, gevormd door zanden met een hoog gehalte aan ronde matte korrels. Dit zou dan van de Günz I glaciatie moeten zijn, die zich in Engeland deed kennen door een plotseling optreden van „koude” mollusken in het Newer Red Crag. Op bovengenoemde tabel zou dat niveau in het Amstelien moeten vallen. Dit is dan in overeenstemming met de Amstelienregressie, een zeespiegeldaling te dien tijde veroorzaakt door het vastliggen van veel ijs op de poolkap. Georges. Dubors (1924) vermeldt, dat ook voor Denemarken, ,les phases glaciaires ont été sensiblement synchroniques des oscillations générales négatives du niveau marin." De Günz II glaciatie wordt in Engeland aangeduid door wéér een plotseling optreden van „koude mollusken" en wel in het Weybourne Crag. De Tegelse klei is zeker ouder dan dat Crag, maar jonger dan het Newer Red Crag en moet dan ook, mede op grond van het zoogdiergezelschap gerekend worden tot het Günz-interstadiaal.

Het „Poederlien d'Anvers” acht Charles Depéret (I9I2) wegens de „présence certaine" van Cervus pardinensis synchroon met het Calabrien van Frankrijk. Dit is een aanwijzing voor de aanname, dat de Kempense klei vóór de eerste glaciatie moet wonden gesteld en dus ook daarom ouder is dan de Tegelse. Ten Dam en Reinhold (r94I, p. 23) zagen in het Foraminiferengezelschap van het Zeeuwse Poederlien al een eerste aanduiding van het naderenda boreale klimaat met koude zeestromen, die ongetwijfeld van de in aantocht zijnde Günz I glaciatie het gevolg zijn. DEPÉRET zag onder de fossielen, die „M. HaAs, à Anvers" 2) hem toonde behalve $C$. pardinensis een bot van een paard en een van een slurfdier, maar geen van beide liet een soortbepaling toe, evenmin als de onderkaak met melkgebit van een neushoorn.

Het is jammer, dat Teilhard en Piveteau (1932) de kleien van Tegelen en van de Antwerpse Kempen als identiek beschouwen en schrijven: „Les argiles de la Campine et de Tegelen renferment comme Cerfs actuellement bien caractérisés les trois espèces suivantes: $C$. Ertborni, $C$. teguliensis et $C$. rhenanus (= pardinensis)". Dit is wel de reden, dat TAvernier (1943) meent tot de identiteit van de Kempense en de Tegelse kleien te kunnen concluderen op

2) Het is wel zeker dat met M. HaAs bedoeld is Dr. Georges Hasse, te Antwerpen, die in I9IO (p. 296) mededeelt behalve de uitvoerig door hem beschreven beenderen van de zeerob Alachtherium, in het Poederlien van Antwerpen ook resten te hebben gevonden van Rhinoceros, Elephas, Cervus en Bos. Vermoedelijk bleek aan Depéret, dat het aan Bos toegeschreven bot van Equus was en dat het Elephas genoemde skeletelement even goed van een ander slurfdier (b.v. Mastodon?) zou kunnen zijn. 
grond niet enkel van stratigrafische en lithologische, maar ook van palaeontologische argumenten. De laatste heb ik echter in zijn publicatie over de ouderdom van de Kempense kleien (1942) niet kunnen vinden, want in hoofdstuk 3 „Faune et flore des argiles" wordt wel over de mollusken en zoogdieren van Tegelen gerept, maar er wordt geen enkele soort uit België genoemd. Wel wordt in een voorafgaand hoofdstuk Cervus falconeri uit de Kempen vermeld, maar die komt in Tegelen $\mathrm{n}$ ie $\mathrm{t}$ voor, evenmin als Elephas antiquus, waartoe van Straelen (1920) meent een kies te kunnen brengen van Ryckevorsel, dezelfde plaats waar vandaan reeds in 1905 EUGÈne DuboIs een geweitak van $C$. fa.coneri heeft beschreven. Aangaande deze olifantskies merkt HaLet (I920) op, dat de juiste laag waar die uit te voorschijn kwam niet bekend is. Het is best mogelijk, dat die uit een jongere deklaag omlaag is gevallen in de groeven.

Van de 2I met zekerheid van Tegelen bekende en beschreven zoogdiersoorten is nog geen enkele in de Belgische kleien gevonden. En het zou, gezien de geringe afstand van de Maasoever bij Venlo tot de buurt van Turnhout, toch wel uiterst vreemd zijn, dat daar niet terzelfder tijd dezelfde zoogdieren geleefd zouden hebben. Op palaeontologische gronden is de Kempense klei zeker $n$ iet synchroom te achten met de Tegelse. De laatste acht ik nog steeds jonger, zij het ook niet veel, dan de klei uit de Antwerpse Kempen (Schreuder, 1944, p. 55 en I945a, p. I9I). Onder de „zwarte fossielen” is er geen enkele soort die ook in Tegelen is gevonden.

Het grondig bestudeerde grote hert uit de Antwerpse Kempen is duidelijk verschillend van Eucladoceros tegulensis ${ }^{3}$ ) van Tegelen, zoals door KUNST (1937) aan een rijk materiaal van beide vindplaatsen in de musea te Leiden, Haarlem, Middelburg, Brussel en te Londen kon worden vastgesteld. Tot dezelfde conclusie kwamen ook Teilhard en Pivereau (1932, p. 9). En het kleine hert uit de Antwerpse Kempen is een ander dan $C$. rhenanus van Tegelen, en door de ervaren zoogdierpaleontoloog Charles Depéret met zekerheid herkend als $C$. pardinensis, die het eerst werd beschreven van de Onder-Villafranchien fauna van Perrier in Auvergne ${ }^{4}$ ).

Een andere conclusie van TAvernier is, dat beide kleien afgezet zouden zijn in het Günz-Mindel interglaciaal, een mening, waartegen ik reeds her-

3) Door de zeer gewaardeerde medewerking van Professor Dr. S. Schaub, te Bazel, is Teylers Museum thans in het bezit van een gemonteerd gewei van Eucladoceros tegulensis (Dubois), ( ${ }^{\circ} \mathrm{I} 5776$ ), waarvan de linker geweitak het typestuk is van de soort en afgebeeld werd door DuBors (1904, p. 247). Dit stuk was echter door de bezitter, de arts L. Stijns, te Roermond, onjuist gerestaureerd, zoals Dubois (1904, corrigenda en addenda, p. 453) opmerkte. Het volgende jaar (IS05, pl. I, fig. I) gaf DuboIS weer een foto van deze geweitak en in de tekst een afbeelding, hoe het stuk er na juiste restauratie zou uitzien. Bij gebrek aan technische hulp in Teylers Museum is Professor Dubors echter niet tot een hernieuwde restauratie gekomen. Tot onze grote voldoening is dit thans door Professor Schaub in Bazel geschied. De rechtertak is een gipsmodel naar de gerestaureerde linkertak vervaardigd.

4) Over C. rhenanus en $C$. pardinensis zie ook ScHaUb, I94I en 1943. 
haaldelijk ben opgekomen (1942, 1943, p. 428 en 1945a, p. I97). Ook andere paleontologen en geologen, als ZEUNER en HELLER delen de opvatting, dat de Tegelse klei onmogelijk jonger dan Günz-interstadiaal zijn kan. De zoogdierfauna van daar is aanmerkelijk ouder dan die van het Cromer Forest Bed, die van Mosbach en van Mauer, etc. Tot mijn voldoening wordt deze opvatting, behalve door de jongere generatie (ZonNEveld, 1947, p. I55, etc.), thans ook door Dr. Tesch gedeeld.

Beschouwen we de door zwarte zoogdierfossielen vertegenwoordigde fauna wat nader, dan doet de gazelle daarin vreemd aan. Deze slanke antilope is thans toch gebonden aan woestijn- en steppegebieden, en daarvan kan om de plio-pleistocene Noordzee geen sprake zijn geweest, evenmin in Limburg als in Zuidoost Engeland, waar NEwToN (1884) Gazella anglica aantoonde en Hinton (I906 en 'o8) Gazel! a daviesii, beide in de jongere Cragformaties. De grootste omzichtigheid moet betracht worden bij het afleiden van een vroeger klimaat uit het voorkomen van fossiele overblijfselen, hetzij van zoogdieren, hetzij van lagere dieren, die vroeger wel andere eisen aan hun milieu kunnen gesteld hebben dan thans.

Zo zou het b.v. wel zeer speculatief zijn om tot de aanwezigheid van drijfijs om de plio-pleistocene Noordzee te concluderen op grond van de aanwezigheid van walrusfossielen in de toen gevormde littorale sedimenten in de ondergrond van Antwerpen en de Zeeuwse wateren. Toch is de walrus thans een echt arctisch dier en te beschouwen als een littorale drijfijsvorm. Zijn gewone verblijfplaats is op, of vlak bij, de kust op het zich daar bevindende pak- of drijfijs, welks grenzen hij slechts zelden verlaat, en dan nog om in kuddeverband andere voedselgronden te zoeken. De zeer grote dieren leven van Crustaceeën, mollusken en wormen, die ze met hun machtige, dolkvormige hoektanden in de bovenkaak uit het slik aan de voet van het ijs loswoelen, dan met hun vervaarlijke snorren bijeenvegen, met behulp waarvan ze de hoopjes, zeer hoorbaar, opslurpen. Ook zijn vissen en zeehonden bij gelegenheid hun prooi. Tegenwoordig raakt slechts hoogstzelden (REDEKE, 1927) een walrus tot op onze breedten verdwaald, maar nog in historische tijden moeten ze langs de kusten van Noord- en Oostzee niet zeldzaam zijn geweest. Ook toen nog waren ze dus minder dan thans aan het ijs gebonden.

Is de walrus al een reus onder de huidige zoogdieren, waarvoor BREHM als lengte opgeeft: tot $4.5 \mathrm{~m}$, het uitgestorven geslacht Alachtherium moet nog groter zijn geweest, want na vergelijking van beider beenderen schat van Deinse de grootte van Alachtherium op $5 \mathrm{~m}$. Hasse heeft aan een schedel uit de ondergrond van Antwerpen een hoektandalveole gemeten met een doorsnee van Io bij $6.5 \mathrm{~cm}$; een losse hoektand (I9II) moet $45 \mathrm{~cm}$ lang zijn geweest, met een basisdoorsnee van 8 bij $6 \mathrm{~cm}$.

Van Obobenus onderscheidt Alachtherium zich o.a. door een minder gereduceerd gebit, want volgens HASSE is de formule van het bovengebit 
$\mathrm{i}: 2$, c $: \mathrm{I}, \mathrm{p}+\mathrm{m}: 5$, terwijl bij de recente walrus, Odobenus rosmarus, een formule bezwaarlijk te geven is, want gedurende het gehele leven van het dier neemt het aantal snijtanden en kiezen af, zodat bij oudere dieren beiderzijds slechts één snijtand voorkomt en vaak niet meer dan drie kiezen. VAN DEINSE noemt vier kiezen normaal voor een volwassen walrus. De formule zou dan zijn: i : I, c : I, p + m: 3 of 4 .

Onder de dieren die we thans van de ,zwarte” fauna kennen, blijken zowel zee- en kust- als bosbewoners te zijn. Van de laatste zijn vooral typerend de zeer grote olifant, Archidiskodon planifrons, en de mastodont met alleen in de bovenkaak twee grote stoottanden, Anancus arvernensis. Voor bijzonderheden over beide kan ik verwijzen naar OsBorn's Proboscidea (1936-1942) en naar mijn publicaties van 1944 en $1945^{b}$.

De op dezelfde vindplaatsen in de Zeeuwse wateren als zwarte fossielen vertegenwoordigde Cetaceeën worden hier buiten beschouwing gelaten, daar hun resten wel van gestrande exemplaren afkomstig zijn, die niet tot de hier thuis behoord hebbende fauna kunnen worden gerekend. Ze zijn uitvoerig behandeld door Dr. A. B. van Deinse, die sinds 1926 geregeld ook over de fossiele vertegenwoordigers van deze familie heeft bericht. Reeds in I9I7 vermeldde Max Weber een zwarte schedel van Choneziphius planirostris uit de Westerschelde.

De Noordzee was in het Tertiair een diepe kalme baai van de Atlantische Oceaan en de moerassige bossen zullen zich vooral bij mondingen van rivieren tot dicht bij de zee hebben uitgestrekt, zodat thans de resten van slurf- en hoefdieren naast die van de robben en dolfijnen worden gevonden.

Door de welwillendheid van Drs P. van DER FEen, conservator van het Middelburgse Museum kreeg ik nog een kies in handen van Anancus (Mastodon) arvernensis. Dit stuk (no. 1562) was, toen ik over de Leidse kies van dezelfde soort berichtte (1944), door de oorlogsomstandigheden niet te bereiken. Thans nu beide kiezen met elkaar te vergelijken zijn, valt het meest op, dat ze zeer weinig van elkaar verschillen. Alle twee zijn het de derde kies uit de rechter bovenkaak. Van beide is de kleur „zwart”, d.w.z. dat de overheersende kleur zwartgrijs is met glanzend zwarte partijen op de kroonvlakte waar het glazuur niet te ver is afgekauwd.

Aan de Middelburgse kies is de voorste wortel grotendeels bewaard gebleven. Van de zijkanten is over de gehele hoogte van de kroon, evenals bij het Leidse exemplaar, de dikke glazuurlaag van de kegels afgebroken, zodat daar de kernen van de kegels bloot liggen. Deze bestaan uit dof zwartgrijs tandbeen. Op die breukvlakken is de radiaire structuur van het email goed te zien, evenals de samenstelling dier laag uit een pikzwart dun buitenlaagje, waarbinnen een dikkere grijze zone, die de binnenste laag omsluit, die direct de tandbeenkern omvat, het dikst is, en zwartgrijs.

Evenals het reeds beschreven stuk is ook de Middelburgse kies ten dele bedekt door een korst van Bryozoën (Membranipora) en enige basaalplaatjes 
van de zeepok. De laatste ziet men ook op de kernen der beschadigde kegels; ze bewijzen, dat de zware beschadiging aan beide zijden der kiezen reeds was geschied voor zij op de bodem van de zee vrij lagen, doch nadat zij uit de alveolen waren gevallen, want in de kaak kan die beschadiging niet hebben plaats gehad. Mogelijk zijn ze al eens met de ijzeren beugel van een visnet in onzachte aanraking geweest, want de breuken zijn nog scherp van randen, ook daar waar de wortels afgebroken zijn.

De kies is wat ouder dan de Leidse, want waar aan de laatste, 1944, Pl. III, f. I het voorste juk (kegelrij) op het kauwvlak nog uit twee duidelijk gescheiden delen bestaat, is er slechts één groot dentienvlak te zien op het kauwvlak van het eerste juk bij de Middelburgse kies, waar het tweede juk even ver is afgekauwd als het eerste van het Leidse exemplaar. Voor verdere beschrijving en afbeeldingen moge ik verwijzen naar de publicatie van 1944.

Ook de maten van deze kies zijn als de toen beschrevene van Ierseke, met dien verstande, dat de Middelburgse kies enkele millimeters breder is, n.l. is de breedte $80 \mathrm{~mm}$. Ook dit exemplaar is dus weer van het type der Engelse stukken uit het Red Crag.

De onderhelft van de humerus van Mustela erminea, de hermelijn, is zeer goed geconserveerd. De omranding van het epicondilaire foramen is gaaf. De lengte van het stuk is $19 \mathrm{~mm}$; de breedte aan het distale uiteinde $8.5 \mathrm{~mm}$. Volgens Dr. A. D. HooIJER, die het stuk vergeleek in het Rijksmuseum van Nat. Hist. te Leiden, is er geen verschil met de recente exemplaren, noch in vorm noch in grootte.

De hermelijn is reeds bekend uit het Onderpleistoceen van Midden-Europa en zijn resten zijn gevonden in grotten daterend uit het gehele Pleistoceen. In Nederland komt hij ook thans vrij algemeen voor en ontbreekt er wel nergens, als mogelijk in enkele weidestreken. $\mathrm{Hij}$ is een uitstekend klimmer en zwemmer.

Het is opvallend, dat de ,zwarte fossielen" slechts van enkele plaatsen in de Zeeuwse wateren worden opgegeven. Zo vinden we voor bijna alle resten van het grote hert de Roompot genoemd (Kunst, r937, p. Ior en de tabel daar); voor één stuk „mogelijk Westerschelde bij Terneuzen”. Behalve de Roompot, wordt ook voor de zwarte fossielen vermeld: Oosterschelde bij Ierseke, waar vandaan opgevist zijn een groot humerusfragment van Alachtherium en de kiezen van de olifant en de mastodont, die in 1944 beschreven zijn. In de mond van de Oosterschelde worden ook genoemd de Put van Oostkapelle en „voor Domburg". De gehele zeestrook dus langs de noord- en de noordwest-kust van Walcheren.

Ook in de Westerschelde worden als opvisplaatsen enkele stromen van de mond genoemd, b.v. de Wielingen en het Oostgat, of enkel "bij Breskens". Uit deze buurt zijn de drie fraaie schedels van Odobenus huxleyi opgehaald. Ook in de Westerschelde is er meer oostelijk nog een meermalen genoemde 
vindplaats, n.l. „bij Terneuzen”, waar een zwarte staartwervel van Alachtherium werd opgevist. Zo is er op het kaartje (p. 3) in beide Schelde-armen een stip in de mond getekend en één meer oostelijk, respectievelijk bij Ierseke en bij Terneuzen.

Dr. Reinhold, directeur van de Rijks Geologische Stichting, te Haarlem, die de kaartbladen van Zeeland heeft opgenomen voor de Geologische kaart, maakte er mij op attent, dat juist op bovengenoemde plekken in de Zeeuwse wateren de diepe erosie optreedt met de reeds genoemde stroom- of kolkgaten. Zo bestond er voor de oorlog bij Terneuzen, tussen de twee havens in, een gat van wel $100 \mathrm{~m}$ diepte. Dat zo zware stukken als de kiezen van de mastodont, die meer dan een kilo wegen en die van de olifant van meer dan 5 kilo beduidend verplaatst kunnen zijn na hun vrijkoming uit de wand van de gaten, is wel zeer onwaarschijnlijk. Ze moeten wel als een baksteen naar de bodem van het gat zijn gezonken en hoe ze van daar in een visnet terecht kunnen zijn gekomen is een raadsel.

Even raadselachtig is het dat de fossielen zo zwart zijn, zowel die uit de beide boringen (in Deventer en in Grubbenvorst), als die uit de buurt van Antwerpen 5) en uit de Zeeuwse wateren en dus ook de geweitakken van Eucladoceros falconeri, die uit de Schelde zijn opgevist, maar dat dit niet geldt voor de resten van hetzelfde hert uit de oostelijk van Antwerpen gelegen Belgische Kempen. De geweitak van Merxplas in Teylers Museum (no. I5871) op welks etiket staat vermeld: „Cervus falconeri Dawk.; Argile de la Campine à $3.5 \mathrm{~m}$ de profondeur dans l'argile; Merxplas (Colonie); Don de M. Stroobant; Mars 1908". (dus nà Dubors's publicaties van 1905 en 1907) en die werd afgebeeld door Kunst (1937, pl. IV, fig. I) is zeer donker bruin, maar de hier in de fossielenlijst op p. 4 genoemde skeletelementen van dezelfde herkomst en soort zijn lichter dan het gewei en niet duidelijk van de Tegelse fossielen te onderscheiden. Ook de kies van Anancus arvernensis uit de Beneden-Rijn is zeker geen ,zwart” fossiel.

Het is begrijpelijk, dat dezelfde plaatsen in de Zeeuwse wateren, die bekend zijn voor hun zwarte fossielen, ook genoemd worden voor niet-zwarte fossielen uit andere formaties die in de kolkgaten worden uitgespoeld.

De kaartjes waarop RUTTEN (1907) de vindplaatsen der door hem behandelde pleistocene zoogdieren aangeeft, vermelden slechts Breskens (dus Wielingen) en Zoutelande (dus Oostgat), beide stromen in de mond van de Westerschelde, die ook voor „zwarte fossielen" meermalen worden genoemd.

ZoNNEveld (I942) noemt als herkomst van de Zeeuwse mammoethkiezen in het Rijksmuseum van Geologie te Leiden „Westerschelde bij Terneuzen”

5) Op mijn vraag naar de kleur dezer fossielen, was Dr. HASSE zo vriendelijk mij te antwoorden (Juli I948), dat ,Al de zoogdierfossielen in plioceen gevonden rond Antwerpen gewoonlijk zwart of donker blauw zijn". 
(8 exemplaren) en „Wielingen”; verder nog een stuk van „Roompot” en een van „Kalloo" 6). Andere plekken noemt hij niet.

Niet bekend voor „zwarte fossielen" zijn de Neeltje Jansplaat en de Roggenplaat in de mond van de Oosterschelde, voor de inham van de zuidkust van Schouwen, die door RAVEN (1934, p. 302) worden genoemd als vindplaatsen van enige jongere pleistocene zoogdierresten (rund, w.o. bison, mammoeth, edelhert, reuzehert, zwijn, paard, enz.) in het Geologisch Instituut in Utrecht. Om deze jong-pleistocene fossielen uit te spoelen zijn niet zo diepe kolkgaten vereist.

\section{SUMMARY}

Lower-Villafranchian landmammals lived in the South of the Netherlands when the coastline of the North Sea retired in northern direction during the Plio-Pleistocene transition period. In the province of Zealand their black remains have been fished out of the waters of the Scheldt in the depth of which littoral Poederlian deposits (Amstelian deposits are missing there in Zealand) occur and are eroded by the currents. Also borings in the provinces of Limburg and Guelderland have yielded black fossils of this fauna of which the following species could be stated in the Netherlands: Eucladoceros falconeri (Dawk.), Odobenus huxleyi (Lank.), Alachtherium spec., Anancus arvernensis (Croiz. et Job.), Archidiskodon planifrons (Falc. \& Caut.), Gazella schreuderae Hooijer and Mustela erminea L. This Lower-Villafranchian fauna occurs also in the Red Crag of East-Anglia, in Piémont (Villafranca) and in Auvergne (Perrier, etc.).

This fauna lived in the south of the Netherlands in the forests and along the coast of the North Sea which then was a deep quiet bay covering a strip of East-Anglia, te larger portion of the Netherlands and a small portion of Belgium along the Belgian-Dutch frontier from the North Sea coast to the east

6) De Kaloo is een ondiepte voor de westkust van Walcheren ter hoogte van Domburg en zal dus wel ongeveer samenvallen met de vindplaats „ter hoogte van Domburg", die wordt vermeld voor de zwarte mastodontkies in het Middelburgse Museum ( $n^{\circ}{ }_{1562}$ ).

Op ZoNNEvel.d's kaartje (p. 77) worden wel enkele andere plaatsen aangetekend, maar de reden daarvan is, dat sommige stippen, die de in de Leidse catalogus genoemde vindplaatsen moeten aanduiden, vrij willekeurig geplaatst zijn. De twee mammoethk:ezen, daarin genoemd als afkomstig uit de Oosterschelde (zonder nadere aanduiding) hebben hun stippen (met de nummers 30 en 78) gekregen ten westen van Schouwen. Die stippen hadden even goed geplaatst kunnen worden op elke andere plek in die Schelde-arm, b.v. bij Ierseke. Zo is het ook geenszins vaststaand, dat de met 3 aangegeven kies van Elephas meridionalis uit de mond van de Schelde-armen afkomstig is, zoals het kaartje aangeeft, mogelijk was de vindplaats veel oostelijker; in de catalogus staat volgens $Z$. enkel ,Zeeuwsche wateren". De stip met nummer 27 staat zeker te veel westelijk, want de catalogus vermeldt volgens $Z$.: „Westerschelde tussen Terneuzen en Braakman”, doch de stip staat westelijk in plaats van oostelijk van de Braakman. Dus andere vindplaatsen in de Zeeuwse wateren dan die van de zwarte fossielen behoeven ook voor de Leidse mammoethkiezen niet te worden aangenomen. 
in the direction of the Meuse near Venlo. South of this coast-line a broad communication between England and the continent caused the identity of their mammals in that period.

\section{LITTERATUUR}

Bernsen, J. J. A., 1934. Eine Revision der fossilen Säugetier fauna aus den Tonen von Tegelen, IX, Cervidae. Maandbl. Limb. Gen. 23, pp. 38-46, 7I-77, 82-83, 2 t.fig., 3 pl., 8 tab.

Burck, H., F. Florschürz en P. Tesch, 1948. De stratigrafische grens tuscen het Plistoceen en het Holoceen in Nederland. Geol. en Mijnb. Io (N.S.), pp. 1og-115.

Callueux, A., 1942. Les actions éoliennes périglaciaires en Europe. Mém. Soc. géol. France XXI, 46, pp. 97, 103 .

DAM, A. TEN en Th. Reinhold, 1941. Die stratigraphische Gliederung des niederländischen Plio-Plistozäns nach Foraminiferen. Meded. Geol. Stichting C.V. I.

Deinse, A. B. van, 1931. De fossiele en recente Cetacea van Nederland. Diss. Utrecht.

_-, 1935. Recente vondsten van fossiele Cetacea en Pinnipedia in Zeeland. Hand. 25ste Ned. Nat. en Gen. Congres, Leiden, -p. 298.

- I943/44. Over resten van fossiele en recente Pinnipedia, aangetroffen in Zeeland en elders in Nederland. De Lev. Nat. 48, pp. 84-87, pp. 97-IOI, pp. II I36, 14 t.fig.

Depéret, Ch., I912. Sur l'existence d'une faune de Mammifères du Pliocène supérieur dans le Scaldisien supérieur ou Poederlien d'Anvers. Bull. Soc. Géol. France I2, p. 817.

Dubois, Eugène, I904a. Over een equivalent van het Cromer Forest-Bed in Nederland. Versl. Kon. Akad. Wet. Amsterdam (2) 13, pp. 243-25I, 2 t. fig.

- I I 4 b. Corrigenda en addenda bij de mededeeling: „Over een equivalent van het Cromer Forest-Bed in Nederland". Versl. K.A.W. 13, pp. 453-454.

-, 1905a. L'âge de l'argile de Tegelen et les espèces de cervidés qu'elle contient. Arch. Mus. Teyler, Série II, 9, pp. 605-615, I pl., I t. fig.

- 1905b. Une espèce de cerf d'age icénien (Pliocène supérieur) Cervus Falconeri Dawk., trouvée dans les argiles de la Campine. Bull. Soc. Belge Géol. 19, pp. 121124, I Pl.

—, 1907. Note sur une nouvelle espèce de Cerf des arg:les de la Camp:ne, Corrus Ertbornii n.sp. Taxandria 4, pp. 80-84, I pl.

Dubors, Georges, 1924. Classification du Quaternaire du Nord de la France et comparaison avec le Quaternaire danois. C.R.Ac.Sc. 179 , p. 475.

Hacquaert, A. en R. Tavernier, 1946. Excursions géologiques en Camp:ne sous la direction des professeurs Armand Hacquaert et René Tavernier. C.R. Sess. extraord. Soc. belge de Géol., 19-26 Sept. 1946.

Halet, F. 1920. Remarques sur la communication de M. van Straelen. Soc. Géol. Belge 30, p. 82.

Hasse, Georges, 19ro. Les Morses du Pliocène Poederlien à Anvers. Bull. Soc. Belge Géol. 23, pp. 293-32I, 3 P1., 17 textfig.

-, 1911. Une défense de morse dans le Pliocène à Anvers. Ibid 25, pp. I69-172, 4 t.fig.

Hinton, M. A. C., 1906. Gazella Daviesii, a New Antelope from the Norwich Crag of Bramerton. Proc. Geol. Assoc. 19, pp. 247-251.

-, 1908. Note on Gazella Daviesii, an Antelope from the Norwich Crag. Geol. Mag. n.s., dec. V, 5, p. 445 , pl. XXIII, figs. 4-5.

HoorJer, A. D., 1945. A fossil gazelle (Gazella schreuderae nov. spec.) from the Netherlands. Zool. Meded. 25, pp. 55-64, 1 fig.

KIng, W. B. R. and K. P. OAKLEY, 1949. Definition of the Plio-Pleistocene Boundary. Nature 163, pp. 186-187.

Kunst, C. E., 1937. Die niederländischen pleistozänen Hirsche. 126 pp., 4 pl. en 28 t.fig. Diss. Leiden.

Newton, E. T., I884. On the occurrence of Antelope remains in Newer Pliocene Beds in 
Britain, with the Description of a New Species, Gazella anglica. Quart. Journ. Geol. Soc. 40, pp. 280-292, P1. XIV.

OAKLeY, K. P., 1949. The Plio-Pleistocene Boundary. Geol. Mag. 86, p. 18.

Osborn, H. F., 1936-'42. Proboscidea I en II. - Am. Mus. Press. New-York.

Pilgrim, G. E. (the late), 1944. The lower-Limit of the Pleistocene in Europe and Asia. Geol. Mag. 8I, pp. 28-38.

Raven, Th., 1935. Neue Funde quartärer Säugetiere in den Niederlanden. Proc. K.A.W., 38 , pp. 230-296, 2 t.fig.

Rutten, L. M. R., 1907. Over fossiele Trichechiden uit Zeeland en België. Versl. K.A.W. (2), pp. 798-811, 3 pl.

Schaub, S., 194I. Die kleine Hischart aus dem Oberpliocaen von Senèze (Haute-Loire). Ecl. geol. Helv. 34, pp. 264-271, pl. 17.

-, 1943. Die oberpliocaene Säugetierfauna von Senèze (Haute-Loire) und ihre verbreitungsgeschichtliche Stellung. Ibid. 36, pp. 270-289, 8 t.fig.

SCHREUDER, A., I942. Momenten uit de geschiedenis der Nederlandsche zoogdierfauna. Vakb!ad v. Biologen 23, no. 8, Uitg. Centen, Amsterdam.

-, 1943. Fossil Voles and other mammals (Desmana, Equus, etc.) out of well-borings in the Netherlands. Verhand. Geol. Mijnb. Gen. 13, pp. 399-434, 7 t.fig.

-, 1944. Upper-pliocene Proboscidea out of the Scheldt and the Lower-Rhine. Leidse Geol. Meded. 14, pp. 40-58, 2 Pl., 3 t. fig.

- 1945a. The Tegelen fauna, with a description of new remains of its rare components (Leptobos, Archidiskodon meridionalis, Macaca and Sus strozzii). Arch. Néerl. Zool. 7, pp. 153-204, I Pl., 13 t.fig.

- 1945b. De Mastodont en de Olifant onder de „zwarte fossielen” uit de Zeeuwsche wateren. Verh. Geol. Mijnb. Gen. 14, pp. 437-448, 2 textfig.

Straelen, V. van, 1920. Sur la présence de restes de mammifères dans les argiles de la Campine. Bull. Soc. Belge Géol. 30, pp. 80-81.

Stromer, E., 1939. Das geologische Alter der Gattung Homo im Vergleiche zu dem añderer mitteleuropäischer Säugetiergattungen. Anthr. Anz. Jahrg. 15, pp. 282-284.

T Tavernier, R., 1942. L'âge des argiles de la Campine. Bull. Soc. Belge Géol. 5I, pp. 193-209.

-, 1943. Le Néogène de la Belgique. Bull. Soc. belge Géol. 52, pp. 7-34,

Teilhard de Chardin, P. et P. Piveteau, 1932. Nouvelle étude sur le Cervus ertborni Dub. des argiles de la Campine. Meded. Kon. Nat. Hist. Mus. v. België 8, no. 5, I2 pp., 5 t.fig.

Tesch, P., 1942. De Noordzee van historisch-geologisch standpunt. Meded. Geol. Dienst, Serie A, no. 9. 14 kaartjes en 2 tabellen.

Weber, Max, 1928. Die Säugetieren. 2de druk. G. Fischer, Jena.

ZoNNEveld, J. I. S., I942. Kiezen van Nederlandsche Elephantidae, anwezig in het Rijksmuseum v. Geologie en Mineralogie. Leidsche Geol. Meded. 13, pp. 76-88.

-, 1947. Het kwartair van het Pee!gebied en de naaste omgeving. Diss. Leiden. 22I pp., kaarten en profielen. 